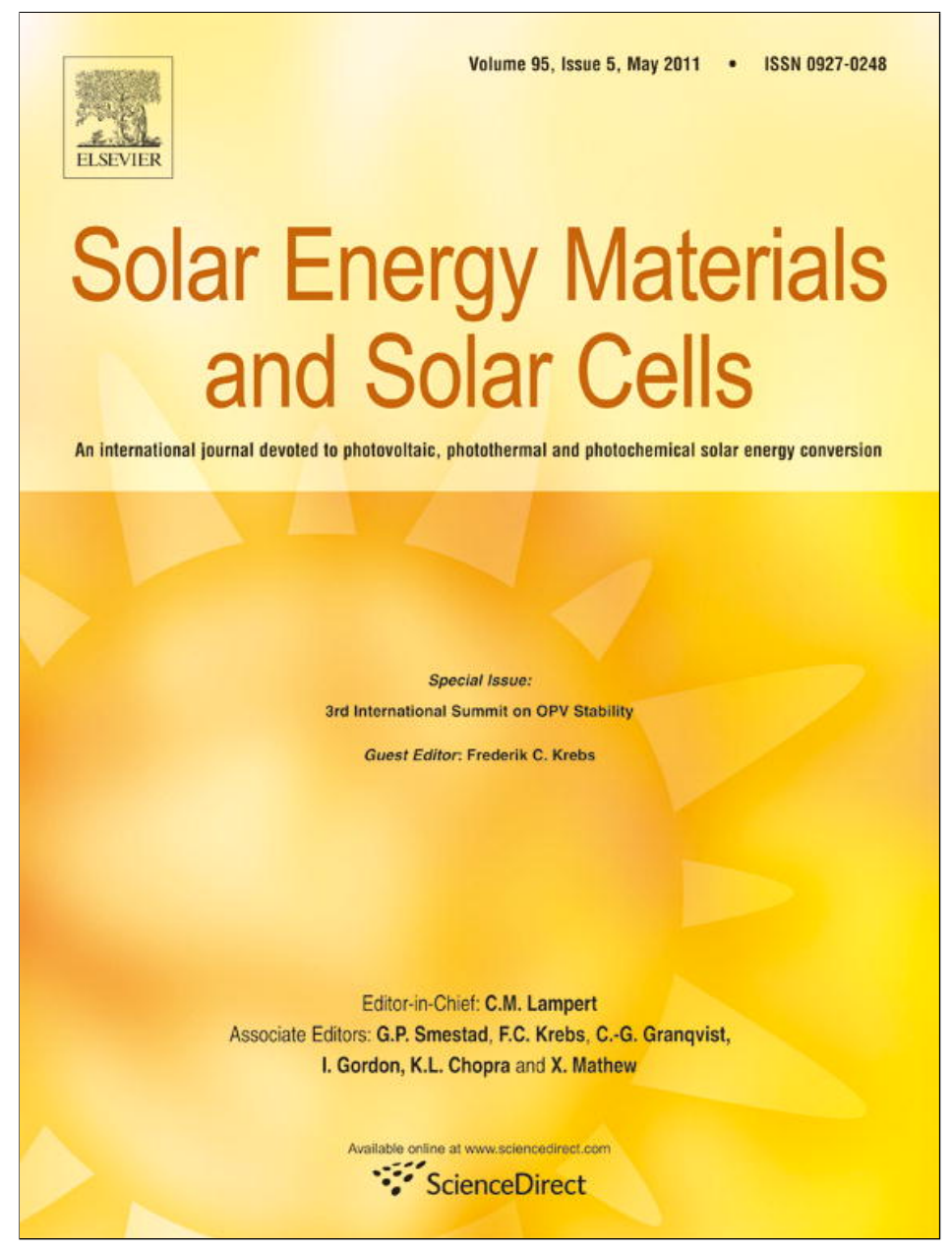

This article appeared in a journal published by Elsevier. The attached copy is furnished to the author for internal non-commercial research and education use, including for instruction at the authors institution and sharing with colleagues.

Other uses, including reproduction and distribution, or selling or licensing copies, or posting to personal, institutional or third party websites are prohibited.

In most cases authors are permitted to post their version of the article (e.g. in Word or Tex form) to their personal website or institutional repository. Authors requiring further information regarding Elsevier's archiving and manuscript policies are encouraged to visit:

http://www.elsevier.com/copyright 


\title{
ITO-free flexible organic solar cells with printed current collecting grids
}

\author{
Yulia Galagan ${ }^{\text {a,*}}$, Jan-Eric J.M. Rubingh ${ }^{\mathrm{a}}$, Ronn Andriessen ${ }^{\mathrm{a}}$, Chia-Chen Fan ${ }^{\mathrm{a}}$, Paul W.M. Blom ${ }^{\mathrm{a}}$, \\ Sjoerd C. Veenstra ${ }^{\mathrm{b}}$, Jan M. Kroon ${ }^{\mathrm{b}}$

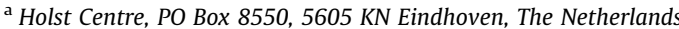 \\ ${ }^{\mathrm{b}}$ Energy Research Centre of the Netherlands (ECN), P.O. Box 1, 1755 ZG Petten, The Netherlands
}

\section{A R T I C L E I N F O}

Article history:

Received 20 July 2010

Received in revised form

30 July 2010

Accepted 10 August 2010

\section{Keywords:}

Organic solar cells

Organic photovoltaics

ITO-free

Current collecting grid

Printed anode

High conductive PEDOT:PSS

\begin{abstract}
A B S T R A C T
The presence of a transparent conductive electrode such as indium tin oxide (ITO) limits the reliability and cost price of organic photovoltaic devices as it is brittle and expensive. Moreover, the relative high sheet resistance of an ITO electrode on flexible substrates limits the maximum width of a single cell. We have developed an alternative ITO-free transparent anode, based on solution processed high conductive PEDOT:PSS in combination with a printed current collecting grid. The screen printed silver grid demonstrates a typical sheet resistance of $1 \Omega / \square$ with $6.4-8 \%$ surface coverage. The efficiency of a flexible device with an active area of $4 \mathrm{~cm}^{2}$ with such a grid is much higher than a similar device based on ITO. Furthermore, as this composite anode is solution-processed, it is a step forward towards low-cost large area processing.
\end{abstract}

(c) 2010 Elsevier B.V. All rights reserved.

\section{Introduction}

The biggest motivation for the development of organic solar cell technology is the low cost potential, based on the use of lowcost materials and substrates and the very high production speeds that can be reached by roll-to-roll printing and coating techniques [1-6]. However, indium-tin oxide (ITO), which is commonly used as a transparent electrode, is one of the main cost consuming elements in present photovoltaic devices [1,7]. The second argument to omit ITO from OPV devices is mechanical flexibility. The brittle ITO layer can be easily cracked, leading to a decrease in conductivity and as a result degradation of the device performance. A third argument is the multi-step patterning of the ITO layer, which involves a lot of chemicals. A lot of effort has been directed on the development of highly conductive polymeric materials such as poly(3,4-ethylenedioxythiophene):poly(4-styrene sulphonate) (PEDOT:PSS). Replacement of ITO by highly conductive PEDOT:PSS has been intensively investigated and reported [8-12]. However, organic photovoltaic devices with only a PEDOT:PSS electrode do not provide high efficiency for large area devices due to the limited conductivity of the PEDOT:PSS, which is typically up to $500 \mathrm{~S} \mathrm{~m}^{-1}$. Improving the conductivity of such a polymeric electrode is possible by combining it with a metal grid, which is either thermally evaporated through micro

\footnotetext{
*Corresponding author. Tel.: +31 404020447 ; fax: +31 404020699.

E-mail address: yulia.galagan@tno.nl (Y. Galagan).
}

structured shadow masks $[13,14]$ or patterned by a lithographic method [15,16]. In Ref. [17] deposition of an Ag grid by diffusion transfer reversal has been reported. Printing of the metal grid, however, is a prerequisite for fully printed OPV devices, enabling low-cost manufacturing. Screen printed silver grids [4] were demonstrated in a roll-to-roll processed inverted OPV device, where the grid is the last printed layer in the devices. Earlier, we have reported inkjet printed current collecting grids as a part of a composite anode in a conventional OPV device [18], where the grid is the first printed layer in the devices. Integration of a conductive grid significantly decreases the resistance of the polymer anode. Despite the fact that single pass inkjet printed current collection grids demonstrate a sheet resistance of $15 \Omega / \square$, which is still a high value for large area devices, it is anyhow better than what can be reached with ITO on a flexible substrate. The conductivity of the grid can be improved by increasing the line height, but the increase in topology of the grid might makes it impossible to overcoat the grid with the subsequent layers. In this paper we report on OPV devices based on a current collecting grid. The metal grid shows a sheet resistance of $1 \Omega / \square$ and is free from topology issues.

\section{Experimental}

A series of organic solar cell devices were prepared on flexible PEN substrates. The layouts of the ITO-based and ITO-free devices are shown in Fig. 1. 

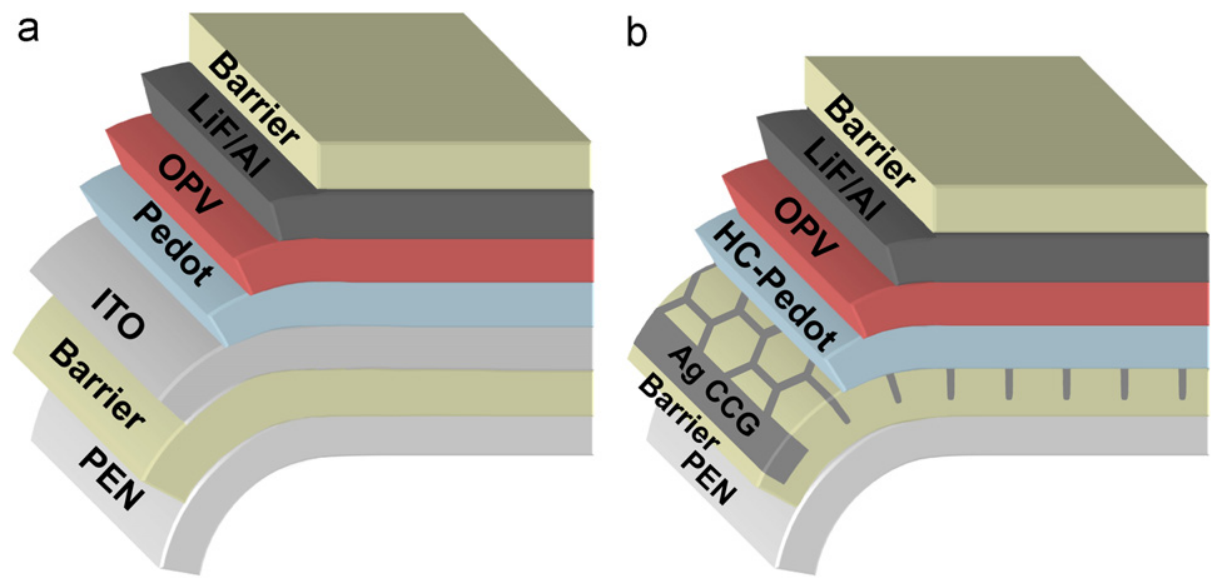

Fig. 1. Schematic illustration of an ITO-based device and a device with a current collecting grid.

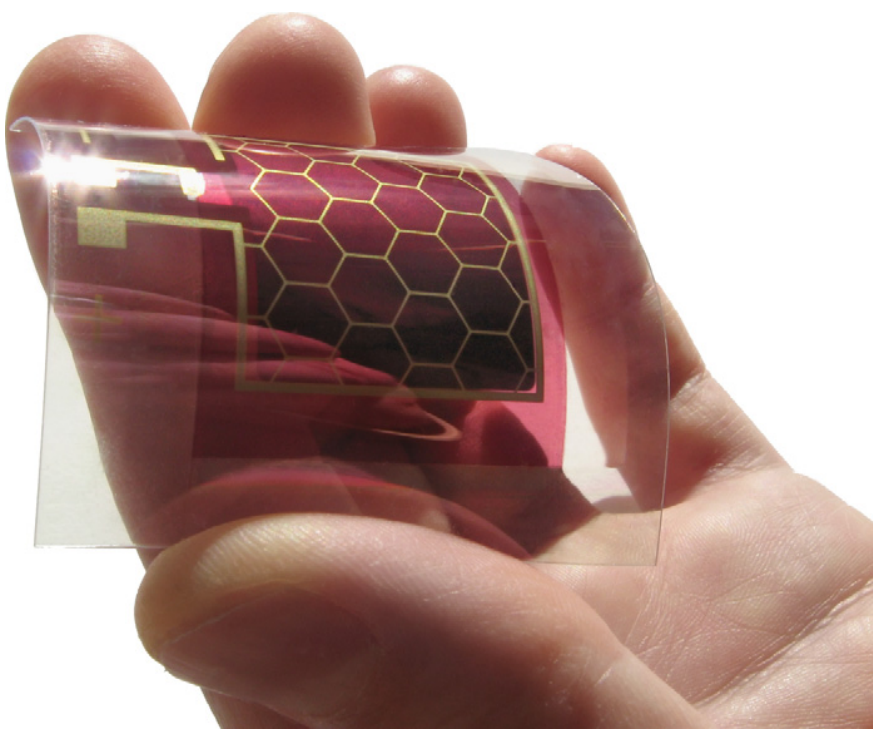

Fig. 2. A picture of the $2 \times 2 \mathrm{~cm}^{2}$ device with current collecting grid, free from ITO.

ITO was sputtered on barrier coated PEN substrates, followed by patterning with photolithography. The sheet resistance of the ITO on the flexible substrates was $60 \Omega / \square$. As a substrate, $125 \mu \mathrm{m}$ thick thermally stabilized PEN from DuPont-Teijin Films was used [19]. The barrier layer was coated using Holst Centre thin film barrier technology [20]. The current collecting grids were screen printed using a DEK Horizon 03i screen printer with a SD40/25 400 mesh screen. As material Inktec TEC-PA-010 hybrid nano silver paste with a silver content of $55 \pm 10 \mathrm{wt} \%$ was used. This silver paste is a blend of silver nano particles and a soluble silver complex. The active area of the devices was $2 \times 2 \mathrm{~cm}^{2}$.

Low conductive PEDOT:PSS (Clevios P VP AI 4083 PEDOT:PSS from H.C. Starck) was used for the preparation of the ITO-based devices. The PEDOT:PSS was spin coated at $2000 \mathrm{rpm}$, resulting in a dry layer thickness of $40 \mathrm{~nm}$ after baking at $150{ }^{\circ} \mathrm{C}$ for $10 \mathrm{~min}$. For the devices free from ITO, the highly conductive Orgacon TM PEDOT:PSS from Agfa-Gevaert was used. Highly conductive PEDOT:PSS was spin coated at $800 \mathrm{rpm}$, resulting in a dry layer thickness of $100 \mathrm{~nm}$. Poly(3-hexylthiophene; P3HT; purchased from Plextronics, Plexcore OS 2100) and [6,6]-phenyl- $C_{61}$-butyric acid methyl ester (PCBM) (99\%, purchased from Solenne BV) were dissolved in 1,2-dichlorobenzene with a mixing ratio of $1: 1$ by weight. The solution was stirred for $14 \mathrm{~h}$ at $70{ }^{\circ} \mathrm{C}$. The photoactive layers were obtained by spin coating of the blend with $4 \mathrm{wt} \%$ of the active materials at $1000 \mathrm{rpm}$ for $30 \mathrm{~s}$, which corresponds to a thickness of $220 \mathrm{~nm}$. The thicknesses of the films were measured using a Dektak profilometer. The experiments are performed in a clean room environment at ambient atmosphere. The metal cathode ( $1 \mathrm{~nm} \mathrm{LiF,} 100 \mathrm{~nm} \mathrm{Al}$ ) was thermally evaporated in a vacuum chamber through a shadow mask. The OPV devices were finished by thin film encapsulation in a glove box. A picture of the $2 \times 2 \mathrm{~cm}^{2}$ device with current collecting grid is shown in Fig. 2 .

Current-voltage curves were measured using simulated AM 1.5 global solar irradiation $\left(100 \mathrm{~mW} / \mathrm{cm}^{2}\right)$, using a xenon-lamp-based solar simulator Oriel (LS0104) 150 W. The light source was calibrated with a standard Si photodiode detector. UV-vis transmission/ absorption spectra were measured using a Perkin-Elmer Lambda $12 \mathrm{UV} /$ vis spectrophotometer.

\section{Results and discussions}

Fig. 3(a) shows a picture of a typical part of a screen printed honeycomb current collecting grid, which is part of the composite anode. The corresponding line profile as shown in Fig. 3(b) is relatively smooth. The effective line width was $160 \mu \mathrm{m}$, the sheet resistance of the printed grid was $1 \Omega / \square$, which is a very good match with the theoretically expected value.

Over-coating of the grid with PEDOT:PSS using spin coating was not successful due to the height of the lines. This problem was solved by embedding the grid into the barrier layer as shown in Fig. 4. The procedure of embedding is an intellectual property of the Holst Centre. In this way, a smooth surface containing the current collecting grid was obtained (see Fig. 4(c)). Grids with both honeycomb and line patterns were printed, as shown in Fig. 5. Honeycomb structure provides more esthetic view of the devices. Moreover, this structure provides homogeneous current distribution in case of four bus-bar devices, which were used in this study. Lines pattern of the grid, which is more applicable for module design, has been compared with honeycomb structure. In this study the pitch sizes (the minimum distance between two conducting lines) and grid's surface coverage were compared. The pitch size was 5 and $2 \mathrm{~mm}$ and surface coverage was $6.4 \%$ and $8 \%$ for the honeycomb and line patterns, respectively.

The current-voltage curves of an ITO-based solar cell and the solar cells with composite anode (current collecting grids and high conductive PEDOT:PSS) are shown in Fig. 6 and the characteristics are given in Table 1. The low fill factor of the ITO-based device is due 
a

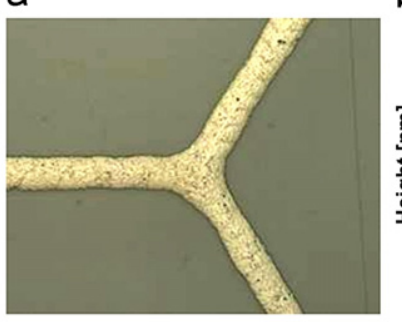

b

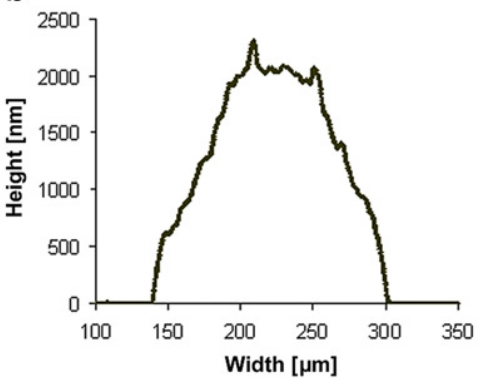

Fig. 3. (a) $50 \times$ microscope image and (b) a typical line profile of screen printed Inktec TEC-PA-010 ink

a

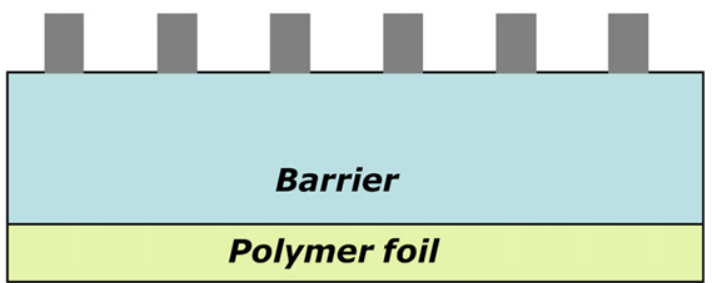

b

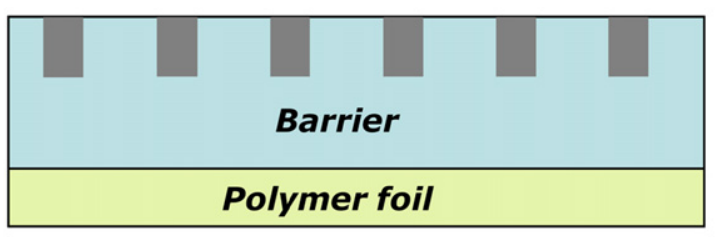

C

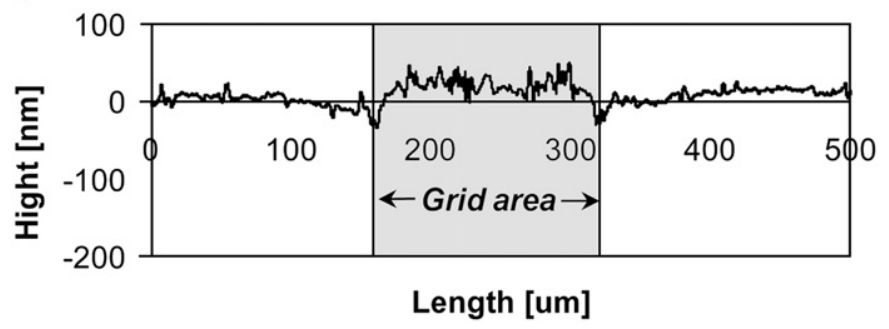

Fig. 4. Schematic illustration of current collection grids: (a) printed on top and (b) embedded into the barrier. (c) Dektak profile of the surface with embedded grid.

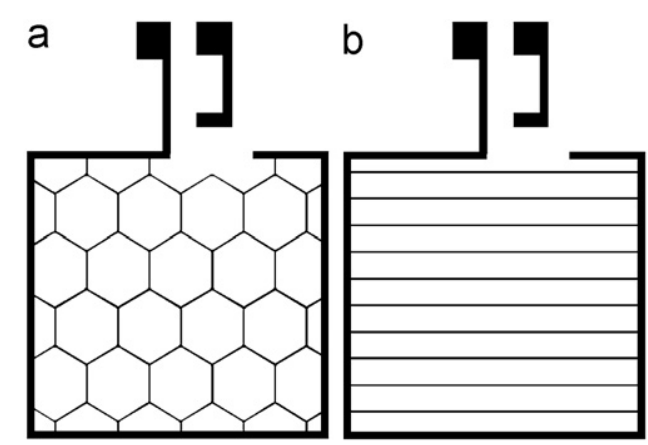

Fig. 5. Conductive grids: (a) with honeycomb and (b) line patterns used for the $2 \times 2 \mathrm{~cm}^{2}$ devices.

to the high sheet resistance of the ITO, which on a foil substrate is typically about $60 \Omega / \square$. Theoretical calculations [21] show that scaling up the size of solar cell devices is not possible without efficiency losses due to the decrease in fill factor. The optimal cell

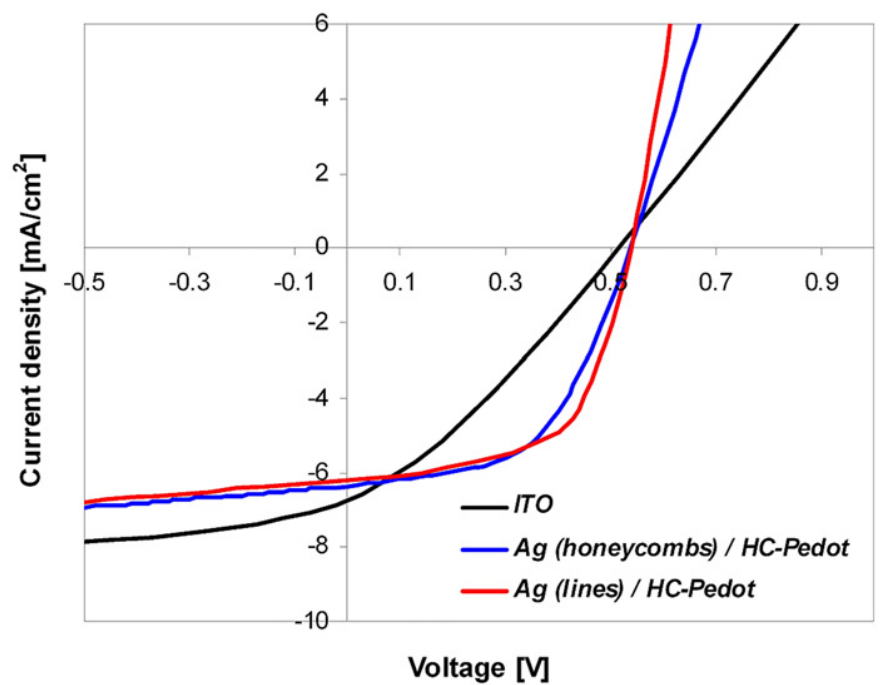

Fig. 6. JV-curves of flexible OPV devices with an active area of $4 \mathrm{~cm}^{2}$ with different anodes: (a) ITO on glass substrate, (b) and (c) high conductive PEDOT:PSS with, respectively, a honeycomb and a line pattern current collecting grid.

Table 1

Characteristics of the photovoltaic devices.

\begin{tabular}{lllll}
\hline Anode & $J_{\mathrm{sc}}\left(\mathrm{mA} / \mathrm{cm}^{2}\right)$ & $V_{\text {oc }}($ Volt $)$ & $\mathrm{FF}(\%)$ & $\eta(\%)$ \\
\hline ITO & 6.59 & 0.489 & 29.60 & 0.95 \\
Ag honeycombs/HC-PEDOT & 6.36 & 0.540 & 53.00 & 1.82 \\
Ag lines/HC-PEDOT & 6.25 & 0.540 & 57.10 & 1.93 \\
\hline
\end{tabular}

width for ITO-based devices on a plastic substrate is in the range $0.5-1.0 \mathrm{~cm}$. The $2 \times 2 \mathrm{~cm}^{2}$ ITO-based device gives a fill factor of $29.6 \%$ and an efficiency of $0.95 \%$. Replacing the ITO by a high conductive PEDOT:PSS (HC-PEDOT) leads to a decrease of the shortcircuit current [18]. This is caused by the high sheet resistance of the HC-PEDOT, which is in the range $200-500 \Omega / \square$. Therefore, it is very important to increase the conductivity of the anode. This is possible by adding a current collecting grid. The difference in current density for devices with such grids versus ITO-based devices can be partly explained by shadow losses due to the grids. Moreover, the difference in the areas covered by the grids also has an influence on the short-circuit current density $J_{\mathrm{sc}}$. Thus, the value of $J_{\mathrm{sc}}$ for the device with the honeycomb grid is higher than that for the device with the line grid. With the honeycomb pattern, $6.4 \%$ of the surface is covered by the grid, while the line pattern covers $8 \%$ of the surface. This explains the difference in the $J_{\mathrm{sc}}$ between the two grid-based devices.

Apart from the shadow losses by the grid, the transparency difference between the double layer ITO/low conductive PEDOT and the highly conductive PEDOT needs to be taken into account. The $120 \mathrm{~nm}$ layer of ITO on PEN provides an average transmittance of $90 \%$ over the visible spectrum $(400-700 \mathrm{~nm})$. The subsequent $40 \mathrm{~nm}$ layer of low conductive PEDOT also absorbs a part of the solar spectrum. The question now is whether this double layer yields lower or higher transparency compared to the $100 \mathrm{~nm}$ thick layer of highly conductive PEDOT. The summarized transmission spectra of the stacks PEN/barrier/ITO/40 nm LC-Pedot and PEN/barrier/100 nm HC-Pedot are shown in Fig. 7.

The transmission spectra indicate that transmittance of light into the photoactive layer is higher in the case of ITO-based device. The $100 \mathrm{~nm}$ thick layer of high conductive PEDOT has a 


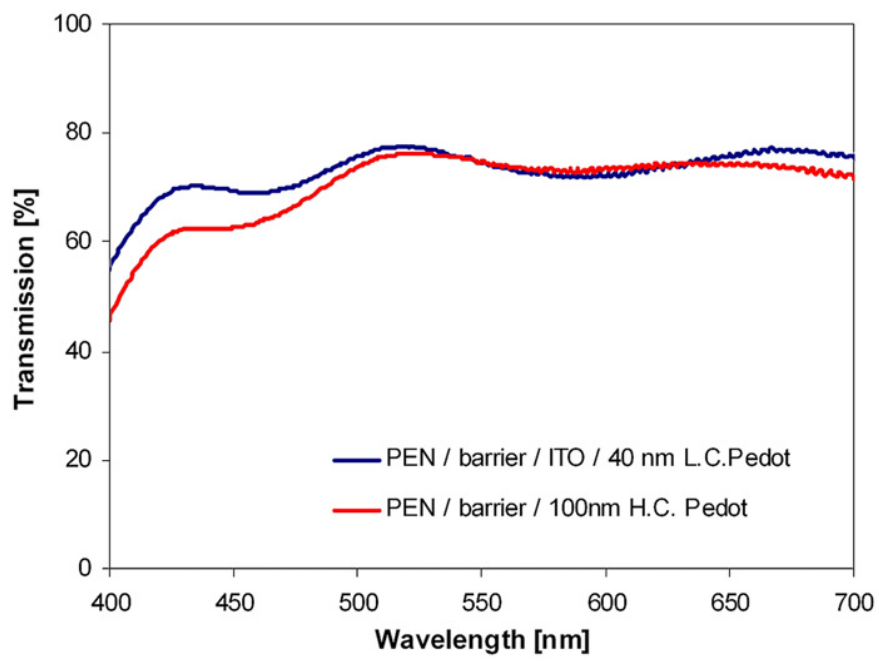

Fig. 7. Transmittance of the device stacks: PEN/barrier/ITO with $40 \mathrm{~nm}$ LC-PEDOT:PSS versus PEN/barrier/with $100 \mathrm{~nm}$ HC-PEDOT:PSS.

relatively high absorption in the visible region. This fact can partly explain the difference in the measured current in both types of devices. Moreover, interference effect should be taking into account. The thickness of the active layer $(\sim 220 \mathrm{~nm})$, according to optical modeling [22,23], was optimal for the ITO-based devices with $40 \mathrm{~nm}$ thick PEDOT layer. Such ratio in the layer thicknesses provides maximum value of $J_{\text {sc }}$. Omitting of ITO and replacement of low conductive PEDOT by high conductive PEDOT with different layer thickness, could lead that interference induced maximum $J_{\mathrm{sc}}$ can be shifted. This means that additional modeling on the optimal thicknesses of the layers is required. Non-optimized layer thicknesses can also contribute to the slightly lower value of $J_{\mathrm{sc}}$ in the ITO-free devices.

Additionally, as already mentioned above, the shadow effect of the grids contributes to the lower current density in the ITO-free devices. The sum of all these factors explains why the current density in ITO-based and ITO-free devices is different. Further improvement of the current density in ITO-free devices is possible by decreasing the shadow effect, by minimizing the line width in the grids and by increasing the transparency of the high conductive PEDOT and optimization of layer thicknesses.

The solar cells with the composite anode versus ITO-based devices show almost the same open-circuit voltage $\left(V_{\text {oc }}\right)$ values, but the fill factors significantly differ. Introduction of a conductive grid with a sheet resistance of $1 \Omega / \square$ into the photovoltaic devices substantially improves the fill factor. As the HC-PEDOT is still responsible for the current collection in the area between the grid lines, the high conductivity of this PEDOT is very important. Moreover, the distance between the grid lines is an important parameter for successful current collection. In Ref. [14] the optimum pitch size has been calculated in wrap-through OPV devices for PEDOTs with different conductivities. In this paper two different pitch sizes have been tested. The results illustrate that the device with the line pattern, with a pitch size of $2 \mathrm{~mm}$, has a higher fill factor than the honeycomb pattern, which has a pitch size of $5 \mathrm{~mm}$.

As the data show, replacing ITO by a composite anode consisting of combination of a metal grid and HC-PEDOT results in a significant increase in efficiency for devices of $2 \times 2 \mathrm{~cm}^{2}$. Future work will concentrate in maximizing the cell area without substantial efficiency losses using optimized grid structures. This will enable a substantial increase of the active area of OPV modules, which in turn will increase the final $\mathrm{Wp} / \mathrm{m}^{2}$.

\section{Conclusions}

Organic solar cells free from ITO on flexible substrates were fabricated. The alternative anode is based on highly conductive PEDOT:PSS in combination with printed current collecting grids. This type of composite anode has a significantly lower sheet resistance in comparison with ITO, which makes larger area devices possible without substantial efficiency losses. The experiments show that the replacement of ITO by a composite anode yields an efficiency increase by a factor of two for devices with an active area of $2 \times 2 \mathrm{~cm}^{2}$. Moreover, the anode is entirely fabricated with solution processing and does not require high temperature annealing nor litho steps. All temperature treatments are compatible with flexible substrates and roll-to-roll processing. Free from the rather expensive vacuum deposited ITO, the composite electrode can significantly decrease manufacturing cost. This work will ultimately contribute towards fully printed devices, which will provide low-cost roll-to-roll manufacturing.

\section{Acknowledgements}

This work has been supported in part by the European Commission as part of the Framework 7 ICT 2009 collaborative project HIFLEX (Grant agreement no. 248678) and by the Dutch ministry of economic affairs of the Netherlands.

\section{References}

[1] F.C. Krebs, Roll-to-roll fabrication of monolithic large-area polymer solar cells free from indium-tin-oxide, Sol. Energy Mater. Sol. Cells 93 (2009) $1636-1641$.

[2] Y. GalaganI. de Vries, A. Langen, R. Andriessen, W. Verhees, S. Veenstra, J. Kroon, Technology development for roll-to-roll production of organic photovoltaics, Chem. Eng. Process (2010), in press, doi:10.1016/j.cep.2010. 07.012 .

[3] F.C. Krebs, Fabrication and processing of polymer solar cells: A review of printing and coating techniques, Sol. Energy Mater. Sol. Cells 93 (2009) 394-412.

[4] F.C. Krebs, Polymer solar cell modules prepared using roll-to-roll methods: knife-over-edge coating, slot-die coating and screen printing, Sol. Energy Mater. Sol. Cells 93 (2009) 465-475.

[5] L. Blankenburg, K. Schultheis, H. Schache, S. Sensfuss, M. Schrödner, Reel-toreel wet coating as an efficient up-scaling technique for the production of bulk-heterojunction polymer solar cells, Sol. Energy Mater. Sol. Cells 93 (2009) 476-483.

[6] A.J. Medford, M.R. Lilliedal, M. Jørgensen, D. Aarø, H. Pakalski, J. Fyenbo, F.C. Krebs, Grid-connected polymer solar panels: initial considerations of cost, lifetime, and practicality, Opt. Express 18 (2010) A272-A285.

[7] F.C. Krebs, T. Tromholt, M. Jorgensen, Upscaling of polymer solar cell fabrication using full roll-to-roll processing, Nanoscale 2 (2010) 873-886.

[8] Y. Zhou, F. Li, S. Barrau, W. Tian, O. Inganäs, F. Zhang, Inverted and transparent polymer solar cells prepared with vacuum-free processing, Sol. Energy Mater. Sol. Cells 93 (2009) 497-500.

[9] S.K. Hau, H.-L. Yip, J. Zou, A.K.Y. Jen, Indium tin oxide-free semi-transparent inverted polymer solar cells using conducting polymer as both bottom and top electrodes, Organ. Electron. 10 (2009) 1401-1407.

[10] B. Winther-Jensen, F.C. Krebs, High-conductivity large-area semi-transparent electrodes for polymer photovoltaics by silk screen printing and vapourphase deposition, Sol. Energy Mater. Sol. Cells 90 (2006) 123-132.

[11] E. Ahlswede, W. Muhleisen, M.W.b.M. Wahi, J. Hanisch, M. Powalla, Highly efficient organic solar cells with printable low-cost transparent contacts, Appl. Phys. Lett. 92 (2008) 143307.

[12] Y.-M. Chang, L. Wang, W.-F. Su, Polymer solar cells with poly(3, 4-ethylenedioxythiophene) as transparent anode, Organ. Electron. 9 (2008) 968-973.

[13] M. Glatthaar, M. Niggemann, B. Zimmermann, P. Lewer, M. Riede, A. Hinsch, J. Luther, Organic solar cells using inverted layer sequence, Thin Solid Films 491 (2005) 298-300

[14] B. Zimmermann, M. Glatthaar, M. Niggemann, M.K Riede A Hinsch, A. Gombert, ITO-free wrap through organic solar cells-a module concept for cost-efficient reel-to-reel production, Sol. Energy Mater. Sol. Cells 91 (2007) 374-378.

[15] K. Tvingstedt, O. Inganäs, Electrode grids for ITO free organic photovoltaic devices, Adv. Mater. 19 (2007) 2893-2897. 
[16] J. Zou, H.-L. Yip, S.K. Hau, A.K.Y. Jen, Metal grid/conducting polymer hybrid transparent electrode for inverted polymer solar cells, Appl. Phys. Lett. 96 (2010) 203301-203303.

[17] T. Aernouts, P. Vanlaeke, W. Geens, J. Poortmans, P. Heremans, S. Borghs, R. Mertens, R. Andriessen, L. Leenders, Printable anodes for flexible organic solar cell modules, Thin Solid Films 451-452 (2004) 22-25.

[18] Y. Galagan, R. Andriessen, E. Rubingh, N. Grossiord, P. Blom, S. Veenstra, W. Verhees, J. Kroon, Toward fully printed organic photovoltaics: processing and stability, Lope-C (2010) 88-91.

[19] I. Yakimets, D. MacKerron, P. Giesen, K.J. Kilmartin, M. Goorhuis, E. Meinders, W.A. MacDonald, Polymer substrates for flexible electronics: Achievements and challenges, Adv. Mat. Res. 93-94 (2010) 5-8.
[20] F.V. Assche, H. Rooms, E. Young, J. Michels, T.V. Mol, G. Rietjens, P.V.D. Weijer, P. Bouten, Thin-film barrier on foil for organic LED lamps, in: Proceedings of the AIMCAL Fall Technical Conference and 22nd International Vacuum Web Coating Conference, 2008.

[21] C. Lungenschmied, G. Dennler, H. Neugebauer, S.N. Sariciftci, M. Glatthaar, T. Meyer, A. Meyer, Flexible, long-lived, large-area, organic solar cells, Sol. Energy Mater. Sol. Cells 91 (2007) 379-384.

[22] A.J. Moule, J.B. Bonekamp, K. Meerholz, The effect of active layer thickness and composition on the performance of bulk-heterojunction solar cells, J. Appl. Phys. 100 (2006) 094503-094507.

[23] A.J. Moulé, K. Meerholz, Minimizing optical losses in bulk heterojunction polymer solar cells, Appl. Phys. B 86 (2007) 721-727. 